\title{
SOCIAL AND INDIVIDUAL FEATURES AFFECTING NATAL DISPERSAL IN THE COLONIAL LESSER KESTREL
}

\author{
David Serrano, ${ }^{1,3}$ José L. Tella, ${ }^{1}$ José A. Donázar, ${ }^{1}$ And Manel Pomarol ${ }^{2}$ \\ ${ }^{1}$ Department of Applied Biology, Estación Biológica de Doñana, Pabellón del Perú, Avda. Ma Luisa s/n, \\ 41013 Sevilla, Spain \\ ${ }^{2}$ Servei de Proteccio i Gestio de la Fauna, Direccio General de Patrimoni Natural, Dr. Roux 80, 08017 Barcelona, Spain
}

\begin{abstract}
Causes of natal dispersal were studied in an isolated population of the migratory, facultatively colonial Lesser Kestrel (Falco naumanni) in northeastern Spain. During a seven-year study, we gathered information on natal dispersal of 751 individuals and on 24 explanatory variables that evaluated individual traits, conspecific cues in terms of colony size, and different ecological and populational features. We examined separately whether or not individuals changed colonies and how far they moved. Dispersal from the natal colony was high (83\%), and dispersers covered a median distance of $7225 \mathrm{~m}$ (range $112-136500 \mathrm{~m})$. The probability of natal dispersal decreased with the size of the natal colony and with the distance to the nearest colony, but not with the distance to unoccupied buildings, in the year of recruitment. Moreover, the shorter the distance to the nearest colony, the shorter the distances that individuals dispersed, particularly to large colonies $(>10$ pairs). These results support the conspecific attraction hypothesis. Accordingly, the probability of recruiting in the natal colony increased with the proportion of philopatric adults, although beyond a threshold individuals were prevented from recruiting by the more dominant adults in a despotic way. The timing of arrival from the wintering grounds was positively related to the probability of colony change, especially in males. To the extent that this variable is related to the phenotypic quality of individuals, it reinforces the idea that natal dispersal is shaped by intraspecific competition in crowded colonies. Males showed lower frequencies of colony change and dispersed shorter distances than did females, as explained by the different role of the sexes in nest acquisition and defense. Our results indicate that natal dispersal is an evolutionarily labile trait simultaneously influenced by ecological, social, and individual features both within and between populations.

Key words: arrival timing; conspecific attraction; facultative coloniality; Falco naumanni; generalized linear mixed models; intraspecific competition; Lesser Kestrel; natal dispersal; sex-biased dispersal; Spain.
\end{abstract}

\section{INTRODUCTION}

Animal dispersal, of paramount importance in population and evolutionary ecology (Greenwood 1980, Johnson and Gaines 1990), involves two main types of movement: natal dispersal, or displacements from birth site to first breeding site; and breeding dispersal, or movements between successive breeding sites (Greenwood 1980). Natal dispersal usually accounts for most dispersal in the life of an individual, so it plays a more critical role in population dynamics and genetic structure of populations than does breeding dispersal (Greenwood and Harvey 1982, Johnson and Gaines 1990). Natal philopatry is thought to be advantageous for individuals because they would benefit from familiarity with resources, predators, and conspecifics. Additionally, philopatry may result in mating with genetically similar individuals, which could preserve coadapted gene complexes (Shields 1982). Moreover, in-

Manuscript received 22 April 2002; revised 1 February 2003; accepted 14 February 2003; final version received 10 March 2003. Corresponding Editor: R. Greenberg.

${ }^{3}$ E-mail: serrano@ebd.csic.es dividuals that move long distances may face higher mortality risks and experience lower fecundity than those settling in or close to the natal site (Waser et al. 1994). However, natal dispersal can produce net benefits including the avoidance of inbreeding and the reduction of competition for resources and mates (Johnson and Gaines 1990).

Studies on natal dispersal classically have been focused on gender-related differences in dispersal patterns (e.g., Greenwood 1980), but the potential roles played by other individual traits at an intrasexual level are far from understood (Massot and Clobert 2000). For example, several models suggest social dominance and individual "quality" as the mechanism causing variability in dispersal decisions (e.g., Gauthreaux 1978, Waser 1985). However, empirical studies have shown contradictory results (Arcese 1989, Brown and Brown 1992, Spear et al. 1998, Verboven and Visser 1998, Wheelwright and Mauck 1998, Altwegg et al. 2000) that could arise from the interaction between the phenotype of the individuals and the quality of the natal site relative to quality of alternative habitats. Thus, the best dispersal tactic for a given phenotype could differ 
among habitats (Verhulst et al. 1997, van der Jeugd 2000).

Coloniality itself may also shape dispersal patterns: colony size (Oro and Pradel 2000, Serrano et al. 2001a), distance from natal colony (Spendelow et al. 1995, Oro and Pradel 1999), and colony saturation (Nager et al. 1996, Negro et al. 1997) can all affect dispersal decisions, but very few studies have considered these aspects in the dispersal of colonial birds.

The Lesser Kestrel (Falco naumanni) is a small, insectivorous colonial falcon of the southern regions of Eurasia. It is a long-distance migrant, wintering in Africa south of the Sahara, and settling on the breeding colonies from late February to early May. First-arriving individuals are adults, whereas firsttime breeders typically arrive later. Males occupy and vigorously defend breeding cavities, whereas females choose among males. Males begin feeding females two weeks before laying and both sexes incubate during 32 days. Firstyear individuals are significantly smaller than older birds, but only males exhibit a transition plumage between fledgling and two-year-old adult. Lesser Kestrels can breed as 1-year-olds, although many individuals delay breeding until their second year of life (Negro 1997; D. Serrano, J. L. Tella, J. A. Donázar, and M. Pomarol, unpublished data).

In this paper, we study the causes of natal colony change and factors influencing dispersal distances in a population of Lesser Kestrels. This species breeds in colonies of varying size as well as solitarily (Forero et al. 1996), which allows us to test for the effect of colony size on dispersal. Our results can be compared to those of Negro et al. (1997), who examined natal dispersal in another population of Lesser Kestrels with different environmental constraints. Our study improves the understanding of the causes shaping natal dispersal in colonial birds by examining the whole range of colony sizes and the spatial distribution of colonies, as well as the potential relationships between phenotypic variability and other traits of individuals with dispersal patterns. The main goals of our study were: (1) to evaluate whether sex, age of recruitment, and other individual traits explain some variation in natal dispersal patterns; (2) to examine the potential roles of colony size variation and the spatial distribution of colonies in dispersal performance; and (3) to identify factors influencing both fidelity to the natal colony and dispersal distances of Lesser Kestrels in relation to other social and populational features such as the presence of close relatives in the natal colony and the level of intraspecific competition.

\section{Hypotheses and predictions}

Phenotypic-and ontogenic-related dispersal hypotheses.-High levels of dominance experienced in the natal brood may be related to competitive skills in the future (e.g., Richner et al. 1989, Velando 2000). Assuming that philopatry is the preferred strategy of Less- er Kestrels, we predicted that high-quality individuals, i.e., those hatched in early dates, with high body condition at fledgling, or with high-ranking status in the brood, should disperse less than less competitive birds ("ontogenic social subordination hypothesis"). Individuals establishing early on the breeding territories have a free choice to settle wherever they want, whereas individuals arriving late could be forced to settle elsewhere due to the establishment of dominance asymmetries in relation to prior residency (Krebs 1982, Cristol 1995). In this way, we expected that individuals arriving early to the breeding grounds should disperse less than individuals arriving late ("Prior settlement hypothesis").

Another two hypotheses concern age of recruitment. Some authors have reported that more competitive individuals recruit earlier in the breeding population than less competitive individuals, thus being more likely to show natal site fidelity or to disperse shorter distances (e.g., Alonso et al. 1997). Accordingly, we predicted that individuals breeding in their first year of life (firstyear recruits) should disperse less than 2-year recruits ("early breeding hypothesis"). On the contrary, individuals could delay breeding until they acquire the competitive abilities and the familiarity with resources necessary to obtain a breeding site in the natal environment, thus dispersing shorter distances than firstyear recruits (Zack and Rabenold 1989). Thus, the alternative "stay-and-foray hypothesis" (see Brown 1987) predicts that second-year recruits should show higher probabilities of breeding in their natal colony or shorter dispersal distances.

Sex-biased dispersal hypotheses.-Two complementary hypotheses have explained sexual asymmetries in dispersal patterns: the "inbreeding avoidance hypothesis" and the "resource defense hypothesis" (Greenwood 1980, Johnson and Gaines 1990). If dispersal has evolved as a mechanism to avoid inbreeding, one or two prerequisites are needed (e.g., Wheelwright and Mauck 1998): (1) dispersal behavior may change in the presence of relatives of the opposite sex, and (2) dispersal should separate kin in space. Accordingly, we expected the probability of colony change to increase with the presence of parents or siblings of the opposite sex in the natal colony, or that the extent of dispersal patterns would be sufficiently asymmetrical between sexes to separate kin in space. On the other hand, Greenwood (1980) suggested that in mating systems based on male defense of resources, males would be more able to acquire a territory in the natal area than elsewhere, whereas females would not be so constrained by such a cost and could be more likely to disperse. Therefore, we expected a female-biased dispersal pattern for the Lesser Kestrel.

Environmental-and social-related dispersal hypotheses.-The conspecific attraction hypothesis predicts that dispersal should be shaped by the presence of conspecifics, so we tested if dispersal distances were af- 
fected by the spatial distribution of occupied buildings ("conspecific attraction hypothesis"), rather than by the distribution of suitable unoccupied buildings ("nest availability hypothesis"). In addition, fitness prospects in our population, as estimated by the number of offspring recruited to the breeding population during the life of individuals, increases with increasing size of the breeding colony (Tella 1996), so colony size could be used as an index of colony quality (Serrano et al. $2001 a$ ). For this reason, we expected dispersal rates to be negatively related to the size of the natal colony and dispersal distances to be affected by the spatial distribution of large colonies ("conspecific attraction hypothesis"). However, because the number of breeding pairs could reflect colony quality in terms of other colony-related characteristics such as nest-hole availability, food abundance, and absence of predators, it could be difficult to distinguish conspecific attraction from other environmental cues closely related to colony size. Most colonies in our population have a surplus of unoccupied cavities (Forero et al. 1996), so availability of nest holes does not determine colony choice. Neither is food supply in the surroundings expected to influence the quality of the colonies, because colony size is not related to the proportion of the preferred foraging habitats around the colonies (Tella 1996). In fact, home ranges of radio-tracked breeding individuals belonging to adjacent colonies of different sizes greatly overlapped in space (Donázar et al. 1995). However, nest predation by nocturnal mammals (brown rats, Rattus rattus, and red foxes, Vulpes vulpes) is the primary cause of nest failure in our population, predation risk being inversely related to colony size (Tella 1996). For this reason, the probability of nest failure may be minimized by recruiting in a colony free of predators. We tested the alternative hypothesis that Lesser Kestrels make their dispersal decisions based on the presence of predators in the natal colony ("predator avoidance hypothesis") and not on the number of conspecifics.

On the other hand, individuals could recruit elsewhere or disperse longer distances when there is strong competition for food, nest sites, or mates in the natal area, so philopatry may be inhibited by crowding (for a review, see Lambin et al. 2001). Accordingly, we predicted that first-breeding Lesser Kestrels would be more likely to disperse when there is strong competition for resources ("intraspecific competition hypothesis").

Finally, kin cooperation may enable individuals to recruit in the natal site, new recruits benefiting from proximity to relatives through reduced aggressions when trying to settle (e.g., Lambin et al. 2001). If this is true, then fidelity to the natal site should be positively correlated with the presence of the parents in the natal colony ("kin facilitation hypothesis").

\section{Methods}

Study population

Our study was conducted in the Ebro Valley, northeastern Spain $\left(\sim 10000 \mathrm{~km}^{2}\right)$, where a Lesser Kestrel population was intensively monitored between 1993 and 1999. Here, colonies were situated in abandoned farmhouses (using cavities under tiled roofs to breed) surrounded by extensive dry-farmed cereal crops (Tella et al. 1998). Occupied buildings during the study period attracted both solitary pairs as well as colonies ranging from 2 to 43 pairs. For simplicity, each building occupied by at least one pair of Lesser Kestrels was defined as a "colony." Distances between neighboring colonies ranged from $50 \mathrm{~m}$ to $12252 \mathrm{~m}$. Our studied population has experienced a marked increase in the last decade (from 224 pairs and 52 colonies in 1993 to 572 pairs and 166 colonies in 1999) due to recent colonization of a traditionally farmed area. Although some colonies were founded each year, $90.8 \%$ of suitable buildings were unoccupied in the last year of study (Serrano et al. 2001b). Further details of the studied population can be found in Serrano et al. (2001a) and Serrano and Tella (2003).

\section{Monitoring the population}

A common problem in studies of dispersal is the emigration of individuals outside of the study area (Koenig et al. 1996). We minimized it by monitoring a large area that contained a whole, isolated population of Lesser Kestrels (see Serrano et al. 2001a, Serrano and Tella 2003). Indeed, the maximum distance between two colonies $(210 \mathrm{~km})$ was much longer than both median and maximum dispersal distances observed $(7.2 \mathrm{~km}$ and $136.5 \mathrm{~km}$, respectively; see $R e$ sults).

From 1993 on, nestlings were marked with a numbered metal band and a plastic color band engraved with an alphanumeric code. Plastic bands were read from hides using spotting scopes. Hand recapture of 1115 banded adults indicated that there was no plastic band loss. Between 1993 and 1998, we banded 4076 fledglings in nearly all colonies of the population. More than $90 \%$ of fledglings were banded each year. Every breeding season, 1994-1999, from February to June, we searched for breeding Lesser Kestrels by visiting most buildings suitable for the species. Occupied buildings were periodically monitored, when we tried to identify all banded individuals and mapped all nests to obtain colony size. From early May, we visited colonies to obtain clutch sizes and early breeding failures. At the largest colonies, nest switching of fledglings may confound the actual brood size of some pairs, so we banded these chicks prior to the age of nest switching (Tella et al. 1997). Finally, we visited nearly all colonies from mid-June to early August to band all fledglings. For each fledgling, we recorded: (1) hatching date, as estimated from the length of the 8th primary feather (Negro et al. 1997); (2) sex, as determined by plumage pattern and coloration (Tella et al. 1996); (3) brood size, defined as the number of fledglings $>21$ days old (Tella 1996); (4) body mass (to the nearest 1 $\mathrm{g})$; (5) rank in the brood, with the largest chick assigned 
TABLE 1. Explanatory variables used to assess the factors affecting the probability of colony change and the dispersal distances between colonies in Lesser Kestrels through GLMM modeling.

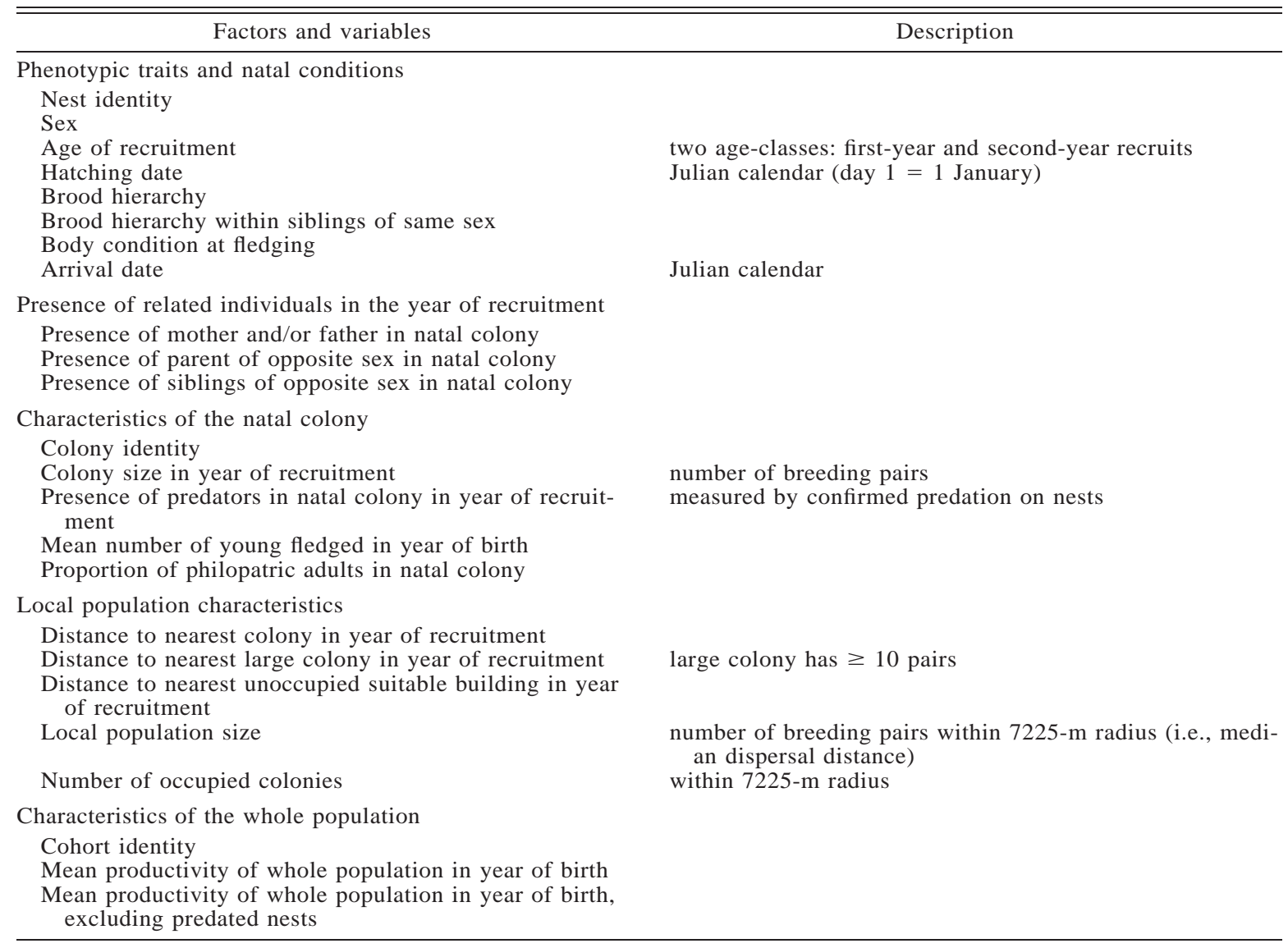

rank 1 , the second largest chick rank 2 , and so on. The body condition of fledglings was calculated as the residuals from the ANCOVA of log body mass as the dependent variable, sex as a fixed factor, year as a random factor, and log length of the 8th primary feather as a covariate $\left(F_{1,409}=18.030, P<0.0001\right)$.

\section{Natal dispersal measurements}

We determined Universal Transverse Mercator (UTM) coordinates of all colonies using a Global Position System. We defined as "dispersers" all individuals that emigrated from the natal colony, and as "philopatric" birds those individuals that showed natal colony fidelity. Dispersal distances were defined as the straight line between the natal colony and the firstbreeding colony. Because Lesser Kestrels can switch colony early in the season, we only considered those mated birds linked to a nest observed during: (1) the two weeks preceding laying (the period of female fertility, maximum copulation rates, and strong pair bonding; (2) incubation; or (3) the chick-rearing period. Therefore, all individuals of doubtful breeding status were removed from our original data set (for the same approach, see Serrano et al. 2001a, Serrano and Tella
2003). This criterion reduced the sample size to $18.4 \%$ of the fledglings banded ( $\sim 53 \%$ of the returning individuals), but guaranteed that we were studying actual and effective dispersal patterns. Therefore, we obtained information on natal dispersal for individuals born in 39 colonies where kestrels bred solitarily, 49 colonies gathering 2-3 pairs, 61 comprising 4-9 pairs, 39 with 10-27 pairs, and 11 colonies with $>27$ pairs of Lesser Kestrels, which reflected well the colony size structure of the whole population (Tella 1996).

\section{Potential factors affecting natal dispersal}

We chose several sets of explanatory variables that could influence dispersal patterns (Table 1). Eight variables reflected phenotypic features and natal conditions that could determine competitive asymmetries among individuals. First observation date in the year of recruitment was used as a measure of arrival date. Three other variables were included to evaluate the effect of presence of close relatives in the natal colony in the year of recruitment. The third variable group reflected characteristics of the natal colony. The size and reproductive success of each colony were chosen because they can be considered as measures of relative 
colony quality (Tella 1996). We also estimated the proportion of philopatric adults in each colony in the year of recruitment. A high proportion of philopatric adults in the natal colony could favor philopatry through conspecific attraction, although beyond a threshold of colony saturation, it could also provoke an increase of intraspecific competition because adults are dominant over first breeders (Serrano 2003). This variable was only calculated in those colonies in which $>50 \%$ of individuals were identified by dividing the number of philopatric adults by the total number of identified birds. The next group of five variables is concerned with local population characteristics around the natal colony, which would indicate both the availability of breeding opportunities and the number of breeding competitors. We considered an unoccupied building as suitable for Lesser Kestrels when it had a tiled roof with cavities similar to those present in occupied colonies (Forero et al. 1996). Finally, we included mean productivity of the whole population (calculated both with and without predation) in the year of birth, as an evaluator of food supply and predation pressure (Serrano et al. 2001a).

\section{Statistical analyses}

We used generalized linear mixed models (GLMMs; see Littell et al. 1996) to identify the factors influencing natal dispersal. GLMMs allow one to incorporate random effects that provide covariance parameters needed when observations are grouped in clusters. In our case, because some fledglings dispersed from the same colony, some individuals from the same nest were recruited, and intercohort variation in dispersal patterns has been detected in this species (Negro et al. 1997), we included colony identity, nest identity "nested" in colony identity, and cohort identity as random terms in the mixed models to account for non-independence of the observations.

We examined separately the probability of colony change and dispersal distance. Because different factors have been shown to influence both decisions (Negro et al. 1997, Forero et al. 1999, 2002, Serrano et al. $2001 a$ ), philopatric individuals were excluded from the second analysis. Probability of dispersing from the natal colony was modeled as a binomial response variable (1, dispersing; 0, not dispersing) using a logistic link function in the macro GLIMMIX of SAS. Log-transformed dispersal distances were employed to model distances covered by dispersers using a normal distribution of errors and an identity link function in the MIXED procedure of SAS. All fixed explanatory variables and their interactions were fitted to the observed data following a forward stepwise procedure. Quadratic and cubic terms were also incorporated into the models to account for potential nonlinear relationships. The result is the most adequate model for explaining the variability in the response variable, where only the significant explanatory variables are retained. We tested for significance of each fixed variable by using $F$ tests, and all $P$ values refer to two-tailed tests.

Given that the proportion of philopatric adults in the natal colony was only available for 399 individuals, and that detailed information on spring arrival dates was only available for a subsample of 343 individuals, we first obtained a mixed model for both colony change and dispersal distance with the whole data set and then tested the effects of arrival date and proportion of philopatric adults by incorporating these variables into the resulting models.

\section{RESULTS}

We gathered information on dispersal performance of 751 individuals (338 males and 413 females). In total, dispersal from the natal colony was high $(82.7 \%)$ and dispersal distances ranged from 112 to $136500 \mathrm{~m}$ (median $=7225 \mathrm{~m}, N=621)$, their distribution being skewed and highly leptokurtic (Fig. 1). Most kestrels $(88 \%)$ recruited in buildings that were occupied in the previous year, the remaining individuals settling in colonies founded in the year of recruitment.

Regarding age of recruitment, we obtained information from 355 first-year recruits (98 males and 257 females), and 396 that recruited in their second year of life (240 males and 156 females). First-year and second-year recruits did not differ in their dispersal frequencies (males, $83.7 \%$ vs. $78.7 \%$, Yates-corrected $\chi_{1}^{2}=0.30, P=0.378$; females, $83.3 \%$ vs. $87.2 \%$, Yatescorrected $\chi_{1}^{2}=0.87, P=0.352$ ). Dispersal distances did not differ regarding age of recruitment (for males, median $6283 \mathrm{~m}$ vs. $5012 \mathrm{~m}$, Mann Whitney $U$ test, $Z$ $=-0.160, P=0.873$; for females, $8815 \mathrm{~m} \mathrm{vs} .7493$ $\mathrm{m}, Z=-0.634, P=0.526)$.

\section{Factors affecting colony change}

Males showed a slight tendency to remain more faithful to the natal colony than did females $(19.8 \%$ vs. $15.3 \%)$. Once potential effects of nest identity $(Z$ $=9.58, P<0.0001)$, colony identity $(Z=1.04, P=$ $0.148)$, and cohort $(Z=0.65, P=0.259)$ were statistically accounted for, we obtained a mixed model for probability of dispersal that retained four variables (Table 2). As predicted, this model showed that probability of dispersal decreased with the size of the natal colony in the year of recruitment (Fig. 2) and with the distance to the nearest colony. The distance to the nearest suitable, but unoccupied, building did not improve our model $\left(F_{1,180}=0.06, P=0.80\right)$. Moreover, the presence of predators in the natal colony, although marginally significant $\left(F_{1,180}=3.79, P=0.053\right)$, entered into the first modeling steps in an opposite way than was expected, probably because large colonies have a greater probability of having at least one nest predated. All of these results suggested that conspecific attraction, not other confounding factors, actually affects natal dispersal patterns. Another important result is that males were less prone to change colony than females (Table 
FIG. 1. Dispersal distances of Lesser Kestrel males (black) and females (white) between the natal and the first breeding colony in the Ebro Valley, Spain.

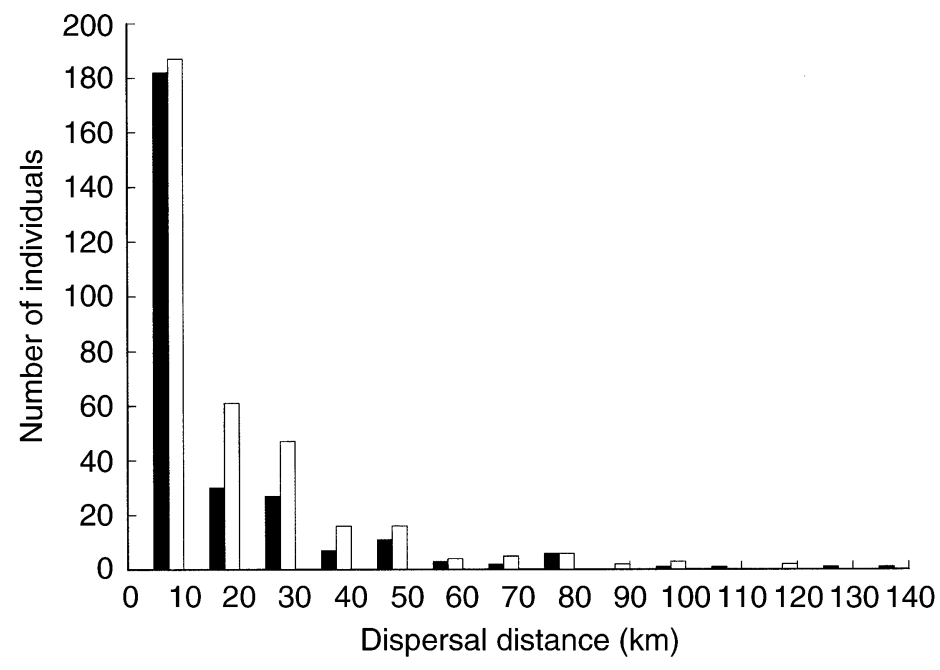

2). Moreover, the probability of dispersing from the natal colony was also affected by the proportion of philopatric adults in a quadratic way when we incorporated this variable into the final model $\left(F_{1,79}=4.78\right.$, $P=0.0318)$. Dispersal rate decreased with the proportion of philopatric adults in the natal colony, but up to a threshold beyond which probability of dispersal increased again (Fig. 3). When the effect of arrival date was included in this model, the effect of the proportion of philopatric adults disappeared $\left(F_{1,18}=0.39, P=\right.$ $0.3921)$. Arrival date showed a strong relationship with probability of dispersal $(0.2794 \pm 0.0389$, mean estimate $\left.\pm 1 \mathrm{sE} ; F_{1,42}=129.75, P<0.0001\right)$. Individuals arriving early to the breeding grounds showed the lowest probability of colony change. There was a significant interaction between sex and arrival date $(0.08868$ \pm 0.03895 for males; $\left.F_{1,42}=5.18, P=0.0280\right)$, indicating that this effect was stronger in males than in females (see Fig. 4).

\section{Factors affecting dispersal distance}

Dispersal distances covered between the natal colony and the first-breeding colony were shorter in males than in females (males, median $=5465 \mathrm{~m}, N=271$; females, median $=9031 \mathrm{~m}, N=350$ ). While controlling for potential effects of nest identity, colony identity, and cohort (all $P$ values $>0.40$ ), the mixed model obtained (see Table 3) showed that dispersal distance was inversely correlated to the distance to the nearest large colony in the year of recruitment (Fig. 5) and also to the distance to the nearest colony, whatever its size. Distance to the nearest unoccupied building, however, did not affect dispersal distance $\left(F_{1,124}=0.05, P=\right.$ 0.82 ). Sex also entered into this model (Table 3 ), showing that males dispersed shorter distances than females.

\section{DiscusSION}

\section{Philopatry vs. dispersal strategies}

Natal dispersal affects most individuals ( 83\%) and accounts for most dispersal in the life of Lesser Kestrels; only $27 \%$ of adult birds changed colony between successive breeding attempts, dispersing a median distance of $1600 \mathrm{~m}$ (Serrano et al. 2001a). However, our results show that the majority of dispersers settled very close to their natal colony (Fig. 1), and only $26 \%$ of natal dispersers moved from the subpopulations (or clusters of colonies spatially separated) where they born (Serrano and Tella 2003). Together, these findings suggest that Lesser Kestrels try to settle within their natal area. By returning to the natal area, individuals could benefit from familiarity with potential breeding sites (Greenwood 1980, Pärt 1995), from mating advantages (Pärt 1994), and even from suffering fewer attacks by resident adults (van der Jeugd 2001). Moreover, philopatry at the population level may have

TABLE 2. Mixed model for probability of colony change between birth and recruitment for Lesser Kestrels.

\begin{tabular}{lllrr}
\hline \hline \multicolumn{1}{c}{ Parameter } & $\begin{array}{c}\text { Parameter } \\
\text { estimate }\end{array}$ & \multicolumn{1}{c}{$1 \mathrm{SE}$} & \multicolumn{1}{c}{$F$} & \multicolumn{1}{c}{$P$} \\
\hline Intercept & 4.7905 & 0.3986 & & \\
Natal colony size & -0.09081 & 0.01469 & 38.22 & $<0.0001$ \\
Distance to the nearest colony & -0.00027 & 0.000089 & 9.55 & 0.0023 \\
Males & -0.5096 & 0.2118 & 5.79 & 0.0171 \\
Explained deviance (\%) & 19.76 & & & \\
Residual deviance & 180.9491 & & & \\
\hline
\end{tabular}




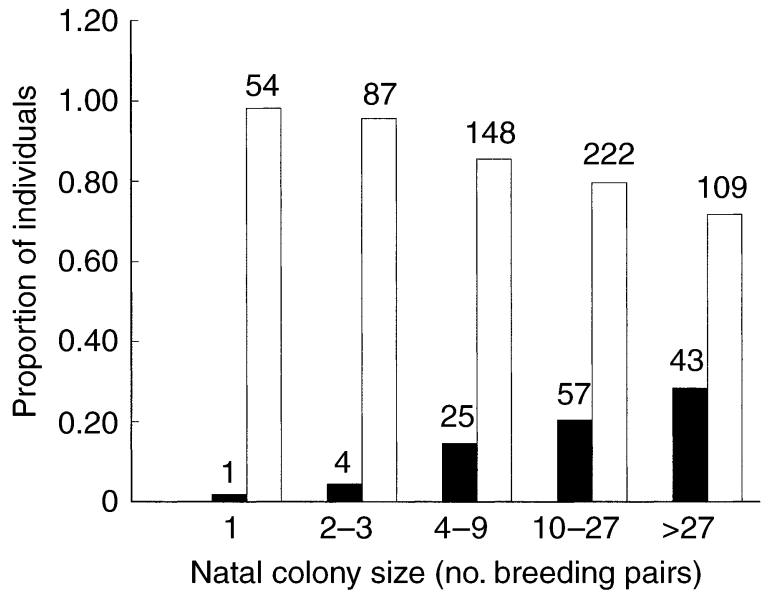

FIG. 2. Frequency of philopatric (black) and dispersing (white) Lesser Kestrels in the Ebro Valley in relation to the number of breeding pairs in the natal colony in the year of recruitment. Sample sizes (no. individuals) are indicated above the bars.

evolved to minimize breeding between individuals carrying alleles adapted to different environments, that is, to maintain local adaptations (Shields 1982).

\section{Density-dependent effects: conspecific attraction vs. competition for resources}

The "conspecific attraction hypothesis" predicts that animals can assess habitat quality indirectly by cueing on the presence and abundance of conspecifics (Stamps 1988, Reed and Dobson 1993). Most Lesser Kestrels recruited in previously existing colonies, in spite of the wide availability of settlement options in unoccupied buildings, suggesting that the presence of conspecifics attracts first-breeding individuals. In addition, the probability of dispersing to other colonies decreased with the size of the natal colony in the year of recruitment, and individuals dispersed shorter distances when there was a large colony in the surroundings. This appears to indicate that Lesser Kestrels use the number of conspecific as an index of colony quality, at least in their natal colony, as was previously found in adult breeding dispersal (Serrano et al. 2001a). Colony size was positively associated with lifetime reproductive success in this species (Tella 1996), so colony size in the year of recruitment is a good indicator of colony quality that may allow birds to avoid time and energy constrains of direct habitat assessment. This point may be decisive for migratory birds because they cannot assess breeding sites throughout the winter. Thus, our findings support the hypothesis that active colony selection occurs in the breeding season of recruitment (see also Spendelow et al. 1995). In fact, first recruits arrive at the breeding grounds much later than adults (D. Serrano, J. L. Tella, J. A. Donázar, and M. Pomarol, unpublished data), when all of the colonies are close to their definitive size (Tella 1996) and can be easily assessed by the intense activity (copulation, mate feeding, etc.) of the previously settled adults.

Dispersal is also affected by the proportion of philopatric adults in a quadratic way. Thus, individuals are more prone to be philopatric when there is a greater proportion of resident adults, again supporting the conspecific attraction hypothesis, but only up to a threshold beyond which this trend disappears. As predicted by the "intraspecific competition hypothesis," our findings appear to indicate that first-breeding birds could be forced to emigrate from natal sites due to social interactions with adults in colonies at carrying capacity (see also Serrano 2003), as has been previously suggested for this species and other colonial birds (Chabrzyk and Coulson 1976, Nager et al. 1996, Negro et al. 1997). Both experimental and correlational studies of migratory birds have shown that resident adults usually evict first breeders from high-quality areas (e.g., Jakobsson 1988). Indeed, yearling and newcomer kestrels searching for a nest hole or a mate are intensively attacked by residents in the breeding colonies (Negro et al. 1997; D. Serrano, J. L. Tella, J. A. Donázar, and M. Pomarol, unpublished data). In this scenario, a large proportion of first-recruited Lesser Kestrels seems to be forced to disperse from the natal colony. This pressure could be very important for colony and population dynamics, as well as for the potential colonization of new buildings once the occupied ones are saturated.

\section{Individual asymmetries in dispersal patterns}

Our multivariable analyses for fidelity to the natal colony identified one individual trait that influences natal dispersal: birds arriving early at the breeding grounds show higher probabilities of natal colony fidelity (Fig. 5), thus supporting predictions of the "prior

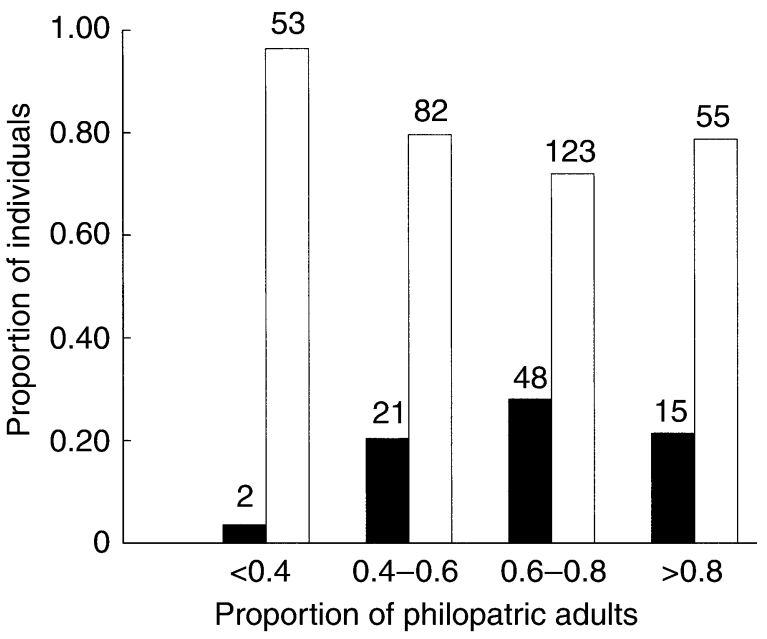

FIG. 3. Frequency of philopatric (black) and dispersing (white) Lesser Kestrels in relation to the proportion of philopatric adults in the year of recruitment. Note that only colonies where $>50 \%$ of individuals identified are represented. Sample sizes (no. individuals) are indicated above the bars. 


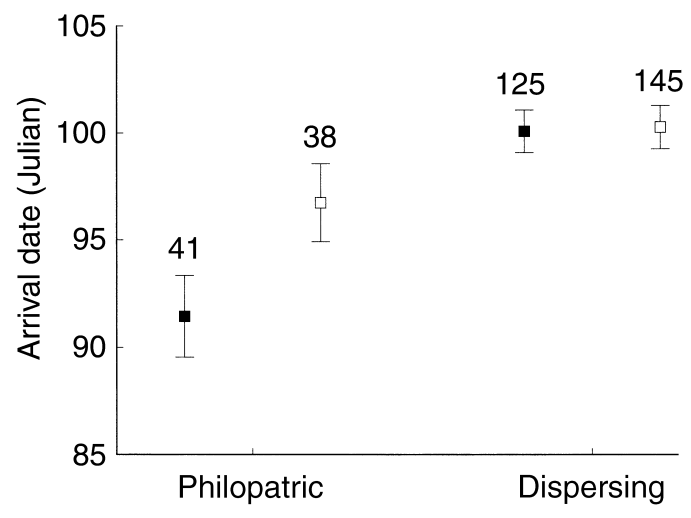

FIG. 4. Pattern of variation in colony change of Lesser Kestrels in relation to arrival date from the wintering quarters (in Julian calendar dates, with day $1=1$ January). Means, standard errors, and sample sizes (no. individuals) for males (solid squares) and females (open squares) are presented.

settlement hypothesis." Moreover, timing of arrival has a larger effect in males than in females, in accordance with sexual asymmetries in the level of intraspecific competition of Lesser Kestrels. Some studies have shown that prior settlement enhances competitive abilities because of "self-confidence" on familiar grounds, so early settlers are usually dominant individuals (Krebs 1982, Cristol 1995) and occupy territories of better quality than late individuals (Ens et al. 1995, Aebischer et al. 1996, Lozano et al. 1996). In migratory birds, it is commonly accepted that only birds in good condition are able to survive the costs associated with early arrival (see review in Kokko 1999), so new recruits arriving early are expected to be individuals of high phenotypic quality (e.g., Møller 1994, Lozano et al. 1996). The relationship between arrival date and philopatry therefore seems to indicate that individuals of high phenotypic quality are able to advance their arrival date, thus effectively competing with others and gaining access to a breeding site in the natal colony. This idea is supported by the fact that the first individuals arriving each spring to the breeding colonies are the experienced, strongly philopatric adults (D. Serrano, J. L. Tella, J. A. Donázar, and M. Pomarol, unpublished data). The fact that the effect of the proportion of philopatric adults disappeared when arrival date was included in the model again supports the idea

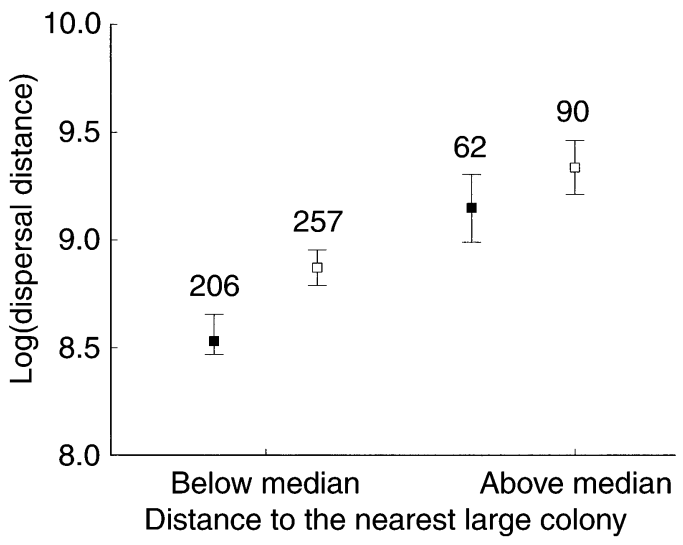

FIG. 5. Relationship between dispersal distance and distance to the nearest large colony (with $\geq 10$ breeding pairs) for dispersing Lesser Kestrels in the Ebro Valley. Means, standard errors, and sample sizes for males (solid squares) and females (open squares) having a large colony below and above the median dispersal distance are represented.

that natal dispersal is shaped by intraspecific competition.

Contrary to the predictions of the "ontogenic social subordination hypothesis," body condition at fledgling, hatching date of individuals, and hierarchy within the brood did not affect natal dispersal. This result could indicate that selection at this level is probably occurring on postfledgling survival (reviewed in Magrath 1991), and that the potential effects of ontogenic traits could change dramatically, depending on the conditions experienced in the wintering areas, which would, in turn, determine the variability in timing of arrival at the breeding grounds among individuals (see Marra et al. 1998).

Regarding gender-based differences, we found that females were less prone to show natal site fidelity and dispersed farther than males, a common result in birds (Greenwood 1980). In our study population, both dispersal propensity and dispersal distance were independent of whether parents or siblings of the opposite sex were present in the natal colony in the year of recruitment, contrary to the "inbreeding avoidance hypothesis." On the other hand, the distribution of dispersal distances of males and females overlapped greatly, so it seems unlikely that sex-biased dispersal could be an

TABLE 3. Mixed model for dispersal distance covered between colony of birth and colony of recruitment for Lesser Kestrels.

\begin{tabular}{lcccc}
\hline \hline \multicolumn{1}{c}{ Parameter } & Parameter estimate & $1 \mathrm{SE}$ & $F$ & $P$ \\
\hline Intercept & 8.7671 & 0.1025 & & \\
Distance to the nearest large & 0.000028 & 0.000008 & 12.02 & 0.0007 \\
$\quad$ colony & & & & \\
Distance to the nearest colony & 0.000062 & 0.000029 & 4.72 & 0.0316 \\
Males & -0.2442 & 0.1067 & 5.23 & 0.0237 \\
Explained deviance $(\%)$ & 12.18 & & \\
Residual deviance & 974.6097 & & & \\
\hline
\end{tabular}


effective mechanism to reduce inbreeding (see also $\mathrm{Ne}$ gro et al. 1997). The "resource defense hypothesis" seems to be the most plausible explanation for the female-biased dispersal performance, because competition between males is mediated through their ability to acquire and defend a nest site and females do not have such a constraint. The probability that males will become established and breed rapidly decreases with time because competition for the number and quality of nests is higher as the breeding season progresses (Tella 1996; D. Serrano, J. L. Tella, J. A. Donázar, and M. Pomarol, unpublished data). Males would increase their breeding prospects by establishing in one of the first breeding vacancies that they find in their natal environment, whereas females would not be constrained by such a pressure and could disperse longer distances to assess mates.

Age of first breeding could be another individual trait affecting dispersal performance. However, both firstyear and second-year breeders showed similar patterns of natal dispersal (see Potti and Montalvo [1991], Forero et al. [2002] for similar results with other species), so we did not find support for the "early breeding hypothesis," or the "stay-and-foray hypothesis." Our study population was far from completely saturated, so assuming low costs of dispersal and equal mortality rates for both sexes (Tella 1996), all individuals could gain access to a breeding opportunity in their first year of life by recruiting in the natal colony or by dispersing elsewhere. Thus, delayed breeding seems to reflect the inability of some individuals to attempt breeding at an early age without suffering fitness costs (e.g., Weimerskirch 1992). This hypothesis was supported by the fact that the proportion of individuals that delay breeding was higher in males than in females, a common finding in raptors, in which males invest more in reproduction than do females (e.g., Lieske et al. 1997). This is the case for the Lesser Kestrel.

\section{Differences between populations}

Natal dispersal performance in Lesser Kestrels can be synthesized in the following ideas: (1) dispersal decisions appear to be strongly influenced by conspecific attraction, i.e., by the size of the natal colony and by the availability of adjacent colonies; and (2) the final dispersal pattern is mediated by the level of intraspecific competition in the natal colony and, especially in males, by competitive abilities as reflected by arrival dates. Thus, both philopatry and dispersal may be optimal strategies to maximize fitness under different ecological scenarios and selective pressures. In this context, we expect that dispersal performance varies not only at the intrapopulation level but also between different populations (see also Forero et al. 2002). Accordingly, Negro et al. (1997) found in Andalusia that $57 \%$ of individuals settled in their natal colony, whereas only $17 \%$ did so in our population. Furthermore, the pattern of dispersal distances differed between popu- lations, with individuals in Andalusia recruiting at median distances more than twice the distances observed in the Ebro Valley (Negro et al. 1997). More surprisingly, Negro et al. (1997) did not find gender-related differences in dispersal patterns. These differences probably reflect asymmetries in social and populational characteristics such as the availability, size, and spatial distribution of the colonies, and the degree of intraspecific competition. A characteristic of our population is the high availability of unoccupied suitable habitat (Serrano et al. 2001b, Serrano and Tella 2003), as is clearly shown by the dramatic population increase experienced during the study period, in comparison with the more stable population of Andalusia. In an unsaturated population with numerous potential breeding sites, individuals prevented from breeding in their natal colony could successfully disperse elsewhere. On the other hand, it could be better to remain in the natal colony queuing for a breeding vacancy when the environment is saturated (Jones et al. 1988, Pruett-Jones and Lewis 1990), the final pattern of dispersal resulting in a higher frequency of philopatric individuals. Moreover, the average distance to the nearest unsaturated site should be longer when general conditions are crowded, thus explaining the longer distances covered by dispersers in Andalusia. The two populations also differ in that median colony size was larger and median distance to the nearest colony was substantially longer in Andalusia than in the Ebro Valley, as a consequence of patchiness of both nesting and foraging habitats (Tella et al. 1998; D. Serrano, J. L. Tella, J. A. Donázar, and M. Pomarol, unpublished data), which might also explain why a larger proportion of birds showed natal philopatry and dispersers generally covered longer distances. To the extent that these multifactorial populational factors could be interpreted as the availability of recruitment options surrounding the natal colony, they could also explain gender-related differences in dispersal behavior between populations (e.g., Potti and Montalvo 1991, Massot and Clobert 2000). For example, the patchiness distribution and degree of saturation of the neighboring colonies in Andalusia could condition the dispersal patterns of individuals, thus masking the relationship between the resource-based mating system and dispersal.

Our results reinforce the current view that dispersal is an evolutionarily labile trait that varies with ecological and social differences both within and between populations (Weatherhead and Forbes 1994). In this sense, future avenues of integrative empirical research explicitly dealing with ecological, social, and individual traits shaping differences between populations should be encouraged.

\section{ACKNOWLEDGMENTS}

The extensive field work necessary to this study was possible thanks to the help of A. Gajón, E. Ursúa, R. López, M. G. Forero, O. Ceballos, Y. Menor, F. Hiraldo, J. M. Grande, I. Luque, R. Jovani, L. Bolonio, F. J. Moreno, E. Pelayo, F. 
J. Sampietro, I. Sánchez, I. Bisson, G. Blanco, C. Sánchez, E. Muñoz, M. Villarroel, J. C. Cirera, F. Hernández, C. Cortázar, J. Blasco, and J. A . Pinzolas, who helped us to monitor individuals and colonies along the years. Manuela G. Forero, Roger Jovani, Diego Gil, Larkin Powell, Russell Greenberg, and an anonymous referee offered important suggestions to improve the manuscript. Financial support was provided by the DGICYT and DGES Projects PB93-0040 and PB96-0834, and by collaborative projects with Diputación General de Aragón (1994-1995) and SEO/BirdLife (1998-1999).

\section{LiTERATURE CITED}

Aebischer, A., N. Perrin, M. Krieg, J. Studer, and D. R. Meyer. 1996. The role of territory choice, mate choice and arrival date on breeding success in the Savi's Warbler Locustella luscibioides. Journal of Avian Biology 27:143-152.

Alonso, J. C., E. Martín, J. A. Alonso, and M. B. Morales. 1997. Proximate and ultimate causes of natal dispersal in the great bustard Otis tarda. Behavioral Ecology 9:243252.

Altwegg, R., T. H. Ringsby, and B.-E. Sæther. 2000. Phenotypic correlates and consequences of dispersal in a metapopulation of house sparrows Passer domesticus. Journal of Animal Ecology 69:762-770.

Arcese, P. 1989. Intrasexual competition, mating system and natal dispersal in song sparrows. Animal Behaviour 38: 958-979.

Brown, C. R., and M. B. Brown. 1992. Ectoparasitism as a cause of natal dispersal in cliff Swallows. Ecology 73: $1718-1723$.

Brown, J. L. 1987. Helping and communal breeding in birds: ecology and evolution. Princeton University Press, Princeton, New Jersey, USA.

Chabrzyk, G., and J. C. Coulson. 1976. Survival and recruitment in the herring gull, Larus argentatus. Journal of Animal Ecology 45:187-203.

Cristol, D. A. 1995. Early arrival, initiation of nesting, and social status: an experimental study of breeding female redwinged blackbirds. Behavioral Ecology 6:87-93.

Donázar, J. A., F. Hiraldo, J. L. Tella, and M. G. Forero. 1995. Establishment of conservation strategies for the lesser kestrel (Falco naumanni) in Los Monegros. Final project report, Wildlife Service, Government of Aragón, Zaragoza, Spain.

Ens, B. J., F. J. Weissing, and R. H. Drent. 1995. The despotic distribution and deferred maturity: two sides of the same coin. American Naturalist 146:625-650.

Forero, M. G., J. A. Donázar, J. Blas, and F. Hiraldo. 1999. Causes and consequences of territory change and breeding dispersal distance in the Black Kite. Ecology 80:12981310.

Forero, M. G., J. A. Donázar, and F. Hiraldo. 2002. Causes and fitness consequences of natal dispersal in a population of Black Kites. Ecology 83:858-972.

Forero, M. G., J. L.Tella, J. A. Donázar, and F. Hiraldo. 1996. Can interspecific competition and nest-site availability explain the decrease of lesser kestrel Falco naumanni populations? Biological Conservation 78:289-293.

Gauthreaux, S. A. 1978. The ecological significance of behavioural dominance. Pages 17-54 in P. P. G. Bateson and P. H. Klofer, editors. Perspectives in Ethology. Volume 3. Plenum, London, UK.

Greenwood, P. J. 1980. Mating systems, philopatry, and dispersal in birds and mammals. Animal Behaviour 28:11401162.

Greenwood, P. J., and P. H. Harvey. 1982. The natal and breeding dispersal of birds. Annual Review of Ecology and Systematics 13:1-21.

Jakobsson, S. 1988. Territorial fidelity of willow warbler (Phylloscopus trochilus) males and success in competition over territories. Behavioral Ecology and Sociobiology 22: 79-84.

Johnson, M. L., and M. S. Gaines. 1990. Evolution of dispersal: theoretical models and empirical test using birds and mammals. Annual Review of Ecology and Systematics 21:449-480.

Jones, E. T., P. M. Waser, L. F. Elliot, N. E. Link, and B. B. Bush. 1988. Philopatry, dispersal, and habitat saturation in the banner-tailed kangaroo rat, Dipodomys spectabilis. Ecology 69:1466-1473.

Koenig, W. D., D. Van Vuren, and P. H. Hooge. 1996. Detectability, philopatry, and the distribution of dispersal distances in vertebrates. Trends in Ecology and Evolution 11: $514-517$.

Kokko, H. 1999. Competition for early arrival in migratory birds. Journal of Animal Ecology 68:940-950.

Krebs, J. R. 1982. Territorial defense in the great tit (Parus major): do residents always win? Behavioral Ecology and Sociobiology 11:185-194.

Lambin, X., J. Aars, and S. B. Piertney. 2001. Dispersal, intraspecific competition, kin competition and kin facilitation: a review of the empirical evidence. Pages 110-122 in J. Clobert, E. Danchin, A. A. Dhondt, and J. D. Nichols, editors. Dispersal. Oxford University Press, New York, New York, USA.

Lieske, D. J., L. W. Oliphant, P. C. James, I. G. Warkentin, and R. H. M. Espie. 1997. Age of first breeding in Merlins (Falco columbarius). Auk 114:288-290.

Littell, R. C., G. A. Milliken, W. W. Stroup, and R. D. Wolfinger. 1996. SAS system for mixed models. SAS Institute, Cary, North Carolina, USA.

Lozano, G. A., S. Perreault, and R. E. Lemon. 1996. Age, arrival date and reproductive success of male American Redstarts Setophaga ruticilla. Journal of Avian Biology 27: 164-170.

Magrath, R. D. 1991. Nestling weight and juvenile survival in the blackbird, Turdus merula. Journal of Animal Ecology 60:335-351.

Marra, P. P., K. A. Hobson, and R. T. Holmes. 1998. Linking winter and summer events in a migratory bird by using stable-carbon isotopes. Science 282:1884-1886.

Massot, M., and J. Clobert. 2000. Processes at the origin of similarities in dispersal behaviour among siblings. Journal of Evolutionary Biology 13:707-719.

Møller, A. P. 1994. Phenotype-dependent arrival time and its consequences in a migratory bird. Behavioral Ecology and Sociobiology 35:115-122.

Nager, R. G., A. L. Johnson, V. Boy, M. Rendon-Martos, J. Calderón, and F. Cézilly. 1996. Temporal and spatial variation in dispersal in the greater flamingo (Phoenicopterus ruber roseus). Oecologia 107:204-211.

Negro, J. J. 1997. Lesser kestrel Falco naumanni. BWP [Birds of the Western Palearctic] Update 1:49-56.

Negro, J. J., F. Hiraldo, and J. A. Donázar. 1997. Causes of natal dispersal in the lesser kestrel: inbreeding avoidance or resource competition? Journal of Animal Ecology 66: 640-648.

Oro, D., and R. Pradel. 1999. Recruitment of Audouin's gull to the Ebro Delta colony at metapopulation level in the western Mediterranean. Marine Ecology Progress Series 180:267-273.

Oro, D., and R. Pradel. 2000. Determinants of local recruitment in a growing colony of Audouin's gull. Journal of Animal Ecology 69:119-132.

Pärt, T. 1994. Male philopatry confers a mating advantage in the migratory collared flycatcher, Ficedula albicollis. Animal Behaviour 48:401-409.

Pärt, T. 1995. The importance of local familiarity and search costs for age- and sex-biased philopatry in the collared flycatcher. Animal Behaviour 49:1029-1038. 
Potti, J., and S. Montalvo. 1991. Return rate, age at first breeding and natal dispersal of Pied Flycatchers Ficedula hypoleuca in Central Spain. Ardea 79:419-428.

Pruett-Jones, S. G., and M. J. Lewis. 1990. Sex ratio and habitat limitation promote delayed dispersal in superb fairy-wrens. Nature 348:541-542.

Reed, J. M., and A. P. Dobson. 1993. Behavioural constraints and conservation biology: conspecific attraction and recruitment. Trends in Ecology and Evolution 8:253-256.

Richner, H., P. Schneiter, and H. Stirnimann. 1989. Lifehistory consequences of growth rate depression: an experimental study on carrion crows (Corvus corone corone L.). Functional Ecology 3:617-624.

Serrano, D. 2003. The role of individual decisions on the metapopulation structure of the lesser kestrel Falco naumanni. Dissertation. Universidad Autónoma de Madrid, Madrid, Spain.

Serrano, D., and J. L. Tella. 2003. Dispersal within a spatially structured population of lesser kestrels: the role of spatial isolation and conspecific attraction. Journal of Animal Ecology 72:400-410.

Serrano, D., J. L. Tella, M. G. Forero, and J. A. Donázar. 2001a. Factors affecting breeding dispersal in the facultatively colonial lesser kestrel: individual experience vs. conspecific cues. Journal of Animal Ecology 70:568-578.

Serrano, D., E. Ursúa, A. Gajón, and J. L. Tella. 2001b. Conservation status and breeding avian species in farmhouses located in the ZEPAs of Los Monegros. Final project report, Wildlife Service, Government of Aragón, Zaragoza, Spain.

Shields, W. M. 1982. Philopatry, inbreeding, and the evolution of sex. State University of New York, Albany, New York, USA.

Spear, L. B., P. Pyle, and N. Nur. 1998. Natal dispersal in the western gull: proximal factors and fitness consequences. Journal of Animal Ecology 67:165-179.

Spendelow, J. A., J. D. Nichols, I. C. T. Nisbet, H. Hays, G. D. Cormons, J. Burger, C. Safina, J. E. Hines, and M. Gochfeld. 1995. Estimating annual survival and movement rates of adults within a metapopulation of Roseate Terns. Ecology 76:2415-2428.

Stamps, J. A. 1988. Conspecific attraction and aggregation in territorial species. American Naturalist 131:329-347.
Tella, J. L. 1996. Ecological constraints, costs and benefits of coloniality in the lesser kestrel. Dissertation. Universidad de Barcelona, Barcelona, Spain.

Tella, J. L., J. A. Donázar, J. J. Negro, and F. Hiraldo. 1996. Seasonal and interannual variations in the sex-ratio of lesser kestrels Falco naumanni. Ibis 138:342-345.

Tella, J. L., M. G. Forero, J. A. Donázar, J. J. Negro, and F. Hiraldo. 1997. Non-adaptive adoptions of nestlings in the colonial lesser kestrel: proximate causes and fitness consequences. Behavioral Ecology and Sociobiology 265:253260.

Tella, J. L., M. G. Forero, F. Hiraldo, and J. A. Donázar. 1998. Conflicts between lesser kestrel conservation and European Agricultural Policies as identified by habitat use analysis. Conservation Biology 12:593-604.

van der Jeugd, H. P. 2001. Large barnacle goose males can overcome the social costs of natal dispersal. Behavioral Ecology 12:275-282.

Velando, A. 2000. The importance of hatching date for dominance in young shags. Animal Behaviour 60:181-185.

Verboven, N., and M. E. Visser. 1998. Seasonal variation in local recruitment of Great Tits: the importance of being early. Oikos 81:511-524.

Verhulst, S., C. M. Perrins, and R. Riddington. 1997. Natal dispersal of great tits in a patchy environment. Ecology $\mathbf{7 8}$ : 864-872.

Waser, P. M. 1985. Does competition drive dispersal? Ecology 66:1170-1175.

Waser, P. M., S. R. Creel, and J. R. Lucas. 1994. Death and disappearance: estimating mortality risks associated with philopatry and dispersal. Behavioral Ecology 5:135-141.

Weatherhead, P. J., and M. R. L. Forbes. 1994. Natal philopatry in passerine birds: genetic or ecological influences? Behavioral Ecology 5:426-433.

Weimerskirch, H. 1992. Reproductive effort in long-lived birds: age-specific patterns of condition, reproduction and survival in the wandering albatross. Oikos 64:464-473.

Wheelwright, N. T., and R. Mauck. 1998. Philopatry, natal dispersal, and inbreeding avoidance in an island population of Savannah Sparrows. Ecology 79:755-767.

Zack, S., and K. N. Rabenold. 1989. Assesment, age and proximity in dispersal contests among cooperative wrens: field experiments. Animal Behaviour 38:235-247. 